\title{
Applying Zipf's Power Law over Population Density and Growth as Network Deployment Indicator
}

\author{
Vagia Kyriakidou*, Christos Michalakelis, Dimitris Varoutas \\ Department of Informatics and Telecommunications, University of Athens, Athens, Greece. \\ Email: bkiriak@di.uoa.gr,michala@di.uoa.gr, arkas@di.uoa.gr \\ Received February $25^{\text {th }}, 2011$; revised May $13^{\text {th }}, 2011$; accepted May $17^{\text {th }}, 2011$.
}

\begin{abstract}
Population distribution analysis contains useful information regarding decision making of networks' deployment. However, both the public and the private sector should decide the development of networks based on qualitative and quantitative criteria, such as the application of power laws. In this work, one of the most widely used power laws applied in demographics, the Zipf's law, is tested over urban cities in Greece. Apart from the examination of Zipf's law validation over population, this study provides further results according the distribution of population density as far as an analysis based on population differentiations in the last decades. According to the results, it is proved that the considered sample plays a crucial role to the final conclusions, since the acceptance or the rejection of the law depends on it. Moreover, important information regarding the deployment of networks are revealed and discussed.
\end{abstract}

Keywords: Population Distribution, Zipf's Law, Population Density, Network Deployment, Population Growth

\section{Introduction}

Urbanization and the process of a city growth have been widely studied and questioned. Apart from important economic and political conclusions, useful information regarding telecommunications/networks development could also be drawn. For example, the deployment of telecommunications networks is usually decided after conducting business models based on estimating the potential users of the offered services. Thus, the analysis of population distribution and growth provides crucial information to decision makers. Initial investments are the main obstacle for operators in order to provide services equally in all areas. Although, despite the increasingly demand for such services e.g. broadband, a digital divide gap between big and smaller cities is still evidence, due to the lack of the required infrastructures.

The European Commission (EC) addressed the problem of these inequalities and in line with its decision for an "Information Society for all" [1] subsidized a number of initiatives aiming to the deployment of telecommunications networks, especially to no-metropolitan areas. The e-Europe 2005 was additionally supported by the action plan i2010 [2], which promoted the advantages of ICT technologies in economical and social aspects. The successor of this action plan is the "Digital Agenda" initiative which will be completed in 2020 and aims to expand ICT benefits [3]. The US government has also confronted the same problem and as Pigg and Clark presented in [4] a number of initiatives are applied by the US Department of Agriculture, targeting to the elimination of technological exclusion in rural areas.

Yet, apart from the total number of population in an area, population density together with population growth should also be included in analyses regarding network development as they contain important information. On the one hand, population density could offer significant economies of scales regarding networks' deployment. On the other hand, the rate of population growth determines the growth of potential users.

The stability regarding cities' size over long time periods in developed countries was investigated among others by $[5,6]$. These works concluded to equal proportions between big and smaller cities. Henderson [7] stated that urbanization process in developing countries releases a number of political and societal challenges. Among others, population agglomeration in urban areas and the change from agriculture to a service-provided economy will raise opportunities for these countries. 
However, it is very likely for policy makers to address income, technological and cognitive diversification between big and smaller cities. These differences are caused mainly because of the distinct policy followed in some areas that favored over others.

Hence, the compliance of a country's population on specific laws provides useful information to decision makers from both the public and the private sector. The evolution of the size distribution seems to be complied with Zipf's law in most cases [8]. According to this rule and in the case of cities size, the second largest city (rank $=2$ ) should have half of the size of the largest one, which is ranked as first (rank $=1)$, the third largest city (rank= 3 ) should have one third of the $1^{\text {st }}$ ranked city, and so on. Thus, this relation, which depends on the population and the rank of each city, can be described by the following equation:

$$
\text { Rank } \times \text { Population }=\text { Constant }
$$

The aim of this work is neither the examination of a new regression method for the validation of Zipf's law nor the critic for the existing models. The paper aims to investigate the compliance of Greek urban areas with the Zipf's law, not only in a population basis but also according to density and $\Delta$ (Population) which represents population differences among last censuses.

The rest of the paper is structured as follows. In Section II the corresponding literature is reviewed and in Section III, the considered sample and the methodology of the analysis are presented. In Section III, the evaluation results are presented and discussed. Finally, in Section IV discussion of the results takes place, while Section $\mathrm{V}$ concludes the analysis and proposes additional applications.

\section{Literature Review}

According to Zipf there is an inversely proportional relationship between the frequency of words in a large corpus and the rank-size of these words. His suggestion is known as the "Zipf's law" [8] and since then it has been applied to several fields of study. The Zipf's law or the "rank-size rule" is one of the most famous rules-among linguists, economists, geographers etc., although it is not based on a clear theoretical basis [9]. Ha et al. [10] investigated the validation of the law between English and Mandarin corpora and Adamic and Huberman [11] proved that web sites' popularity follows the Zipf's law. $\mathrm{Lu}$ et al. [12] claimed that the majority of expressed genes exhibit a power law distribution similar to Zipf's one etc..

Nowadays, the Zipf's law and its applications have attracted the interest of many researchers worldwide and the factors which may affect its validation test are under investigation. According to many researchers, concentration of population and urbanization are related to the Zipf's law. Kosmopoulou [13] studied the distribution in both metro and urban areas in US cities. She concluded that metro areas comply with Zipf's law, while urban areas tend to not follow the law, especially in recent years. Nitsch [14] claimed that the law cannot be valid for urban areas due to the evolution of the modern countries and cities. In addition, an international research showed that the regression method may significantly affect the results of validation tests [15]. Furthermore, Gabaix and Ioannides [16] proposed that city size distribution can be better justified through dynamic models, than by Zipf's law which belongs to power laws.

Sato and Yamamoto [17] investigated the relation between urbanization and demographic transition and they suggested that urbanization plays a crucial role in the process of economic development. In addition, Lucas suggested in [18] that there is a positive relationship between economic development and human capital growth. Thus, public policies have been strongly influenced by the urban growth and population concentration [19]. Cunningham et al. [20] studied the network growth in mobile telephony and concluded, among others, that demographic factors affect the development of this market. Not surprisingly, population density has a positive impact on mobile demand. In addition, income and the distribution of GDP on population, e.g. income inequality, are considered as driving factors regarding the adoption of mobile services. Moreover, Moutafides and Economides [21] showed that income is positively varied with demand for broadband services.

The compliance of population under certain rules, such as the Zipf's law, is strongly depended on the sample size [22]. For this reason, the following analysis is separated in two cases. On the one hand, urban cities with population more than $5 \mathrm{~K}$ inhabitants are studied and on the other hand cities with more than $10 \mathrm{~K}$ are included in the analysis. For both cases, the analysis is conducted with and without the two main urban areas of Greece, which are the capital city of Athens and Thessalonica.

\section{The Methodology}

The data sample used in this analysis were drawn from the official Hellenic Statistical Authority [23], correspond to years 1971, 1981, 1991 and 2001 and they are the only data digitally available from corresponding censuses. Before the explanation of the exact following methodology, it must be clear that the dataset was defined based on cities which were characterized as urban by the National Census in 2001 (approximately $\geq 5 \mathrm{~K}$ inhabitants). However, a decade has almost passed from the last census and so data from 2011 are also included in 
analysis based on forecasted values. Though, a well known model used to forecast population i.e. Gompertz model is applied to the observed data so as to estimate population for 2011 [24].

The total population of Greece is about 10 million, from which more than $40 \%$ lives in the wider area of the capital city of Athens. According to the last census, conducted in 2001, 63 cities, including Athens and Thessalonica, concentrate about $70 \%$ of the entire population of the country. However, despite the high concentration in the two main metro areas, more than $6 \mathrm{M}$ citizens have chosen to live in smaller cities. In addition, given the fact that the total growth of population from 1971 to 2001 was about $40 \%$, interesting implications for decision makers regarding network development could be raised. The following Table 1 shows the basic statistical measures of the dataset with and without the two main urban areas (numbers are rounded up to the next largest integer number):

As Zipf's law cannot hold except for a certain sample size [25], in case of initially rejection it would be useful to put some limits and test the results again. The limits set in a similar analysis refer to the median of the dataset [26]. This approach is akin to two-sided Zipf's law that Ripeanu et al. [27] and Adamic and Huberman [11] suggested. According to this assumption, there is a noticeable differentiation in results between bigger and smaller cities.

The first test was applied on populations observations, the second one on density and, finally, the third test was applied on $\Delta$ (Population), which is the change of population between subsequent censuses. Hence, a linear regression over the dataset, using the ordinary least squares (OLS) has been applied. The parameters of the following equation were estimated based on the afore-mentioned dataset:

$$
\ln \left(P_{i t}\right)=\alpha+\beta \ln \left(R_{i t}\right)+\varepsilon
$$

where $P_{i t}$ is the population of the city $i$ in time period $t$.

Table 1. Basic statistic measures of urban cities (observed data).

\begin{tabular}{ccccc}
\hline & 2001 & 1991 & 1981 & 1971 \\
\hline \multirow{2}{*}{ Max } & $3.644 \mathrm{~K}$ & $3.442 \mathrm{~K}$ & $3.313 \mathrm{~K}$ & $2.758 \mathrm{~K}$ \\
& $(161 \mathrm{~K})^{*}$ & $(153 \mathrm{~K})^{*}$ & $(143 \mathrm{~K})^{*}$ & $(112 \mathrm{~K})^{*}$ \\
Min & 5.009 & 2.336 & 1.111 & 636 \\
& 49.614 & 45.766 & 43.007 & 35.945 \\
Average & $(18.542)^{*}$ & $(16.686)^{*}$ & $(15.207)^{*}$ & $(12.965)^{*}$ \\
& 8.004 & 7.193 & 6.891 & 6.444 \\
Median & $(7.967)^{*}$ & $(7.191)^{*}$ & $(6.828)^{*}$ & $(6.326)^{*}$ \\
& 146 & 146 & 146 & 146 \\
$\mathrm{~N}$ & $(144)^{*}$ & $(144)^{*}$ & $(144)^{*}$ & $(144)^{*}$ \\
\hline
\end{tabular}

*measures without the two main urban areas (Athens and Thessalonica) and $R_{i t}$ is the rank of city $i$ during the same time period. Through that model the slope beta. $\beta$, and the intercept alpha, $\alpha$, were estimated.

In order to validate the accuracy of the regression, standard statistical measures have been adopted, such as Standard Error of the Estimate (SEE) and coefficient of determination (COD or R-square) which should be more than $90 \%$ for acceptable results, as Kamecke suggested [30].

\section{The Results}

\subsection{Zipf's Law Validation Test for Ranks and Populations}

In the first validation test of the Zipf's law, the compliance of population is tested using Ordinary Least Squares (OLS). The results from the first test are presented in Table 2 and in Figure 1.

According to this test, it can be concluded that the first dataset, where Athens and Thessalonica included, tends to comply with the Zipf's law only in the last census. The slope ranges from -1.181 in 1971 to -1.067 in 2011 and $\mathrm{R}$-square is over acceptable threshold in all cases. Moreover, it seems that the process of rapid urbanization tends to limit significantly, as both slope (b) and the intercept alpha (a) indicated. These results lead to the conclusion that Greek urban cities tend to limit their population differences. Especially during the last decades this conclusion seems to be more valid taking into account that $\mathrm{R}$-square records higher values and the errors are lower. On the other hand, the second dataset, where Athens and Thessalonica are excluded from the analysis, is not complied with the Zipf's law in recent years. In 1971 the

Table 2. Results of ranks and population for all urban cities.

\begin{tabular}{ccccccc}
\hline Year & Case & $\mathrm{b}$ & $\mathrm{a}$ & $\mathrm{R}^{2}$ & $\mathrm{SEE}$ & $\mathrm{N}$ \\
\hline \multirow{4}{*}{2011} & inc.A & -1.067 & 13.793 & 0.965 & 0.198 & 146 \\
& \&Th & $(0.017)$ & $(0.069)$ & & & \\
& exc.A & -0.875 & 12.943 & 0.965 & 0.176 & 144 \\
& \&Th & $(0.016)$ & $(0.064)$ & & & \\
& inc.A & -1.074 & 13.756 & 0.962 & 0.201 & 146 \\
& \&Th & $(0.017)$ & $(0.073)$ & & & \\
& exc.A & -0.880 & 12.897 & 0.954 & 0.182 & 144 \\
& \&Th & $(0.016)$ & $(0.066)$ & & & \\
& inc.A & -1.106 & 13.755 & 0.963 & 0.203 & 146 \\
& \&Th & $(0.017)$ & $(0.073)$ & & & \\
& exc.A & -0.912 & 12.894 & 0.949 & 0.198 & 144 \\
& \&Th & $(0.017)$ & $(0.072)$ & & & \\
& inc.A & -1.157 & 13.828 & 0.954 & 0.239 & 146 \\
& \&Th & $(0.021)$ & $(0.086)$ & & & \\
& exc.A & -0.961 & 12.961 & 0.926 & 0.256 & 144 \\
& $\& T h$ & $(0.022)$ & $(0.093)$ & & & \\
& inc.A & -1.181 & 13.760 & 0.926 & 0.316 & 146 \\
& \&Th & $(0.027)$ & $(0.114)$ & & & \\
& exc.A & -0.987 & 12.899 & 0.878 & 0.347 & 144 \\
& $\& T h$ & $(0.030)$ & $(0.126)$ & & & \\
& \&Th & & & &
\end{tabular}

Errors are in parentheses 

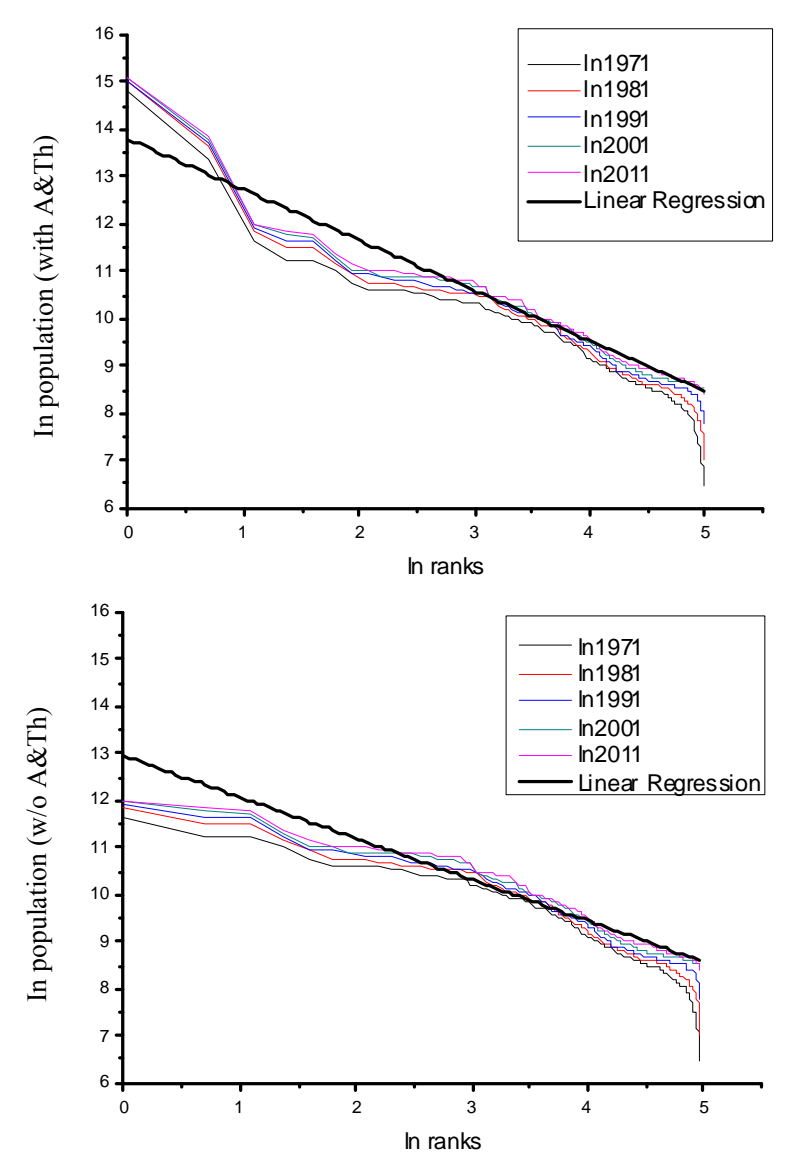

Figure 1. Graphs of logarithms of ranks and population with and without Athens \& Thessalonica.

population was distributed in line with the law. However, in 2011 the slope is not consistent with it. According to these results, it seems that the distribution of population in small urban cities tend not to follow the Zipf's law. Thus, further analysis is provided, in order to determine the law validation over the Greek population.

After separating the sample in two subsets, above and bellow $10 \mathrm{~K}$ inhabitants, Zipf's law validation is tested again with the same method of OLS (Table 3and Figure 2Figure 2). The threshold of $10 \mathrm{~K}$ inhabitants is in line with the initiative "eEurope 2005, an information society for all", aiming to the subsidization of deployment of fiber optical metropolitan networks in urban cities with more than $10 \mathrm{~K}$ inhabitants (www.infosoc.gr).

According to the analysis of the results, the first sub-sets comply with the law, while the second ones give non acceptable results. More specifically, cities with more than $10 \mathrm{~K}$ inhabitants-including Athens and Thessalonica seem to follow a stable population distribution. Statistical results are above threshold of acceptance and the slight increase in the intercept parameter, $\alpha$, indicated the general population increase.
Table 3. Results of ranks and population for urban cities with more than $10 \mathrm{~K}$ inhabitants.

\begin{tabular}{ccccccc}
\hline \multirow{2}{*}{ Year } & Case & $\mathrm{b}$ & $\mathrm{a}$ & $\mathrm{R}^{2}$ & $\mathrm{SEE}$ & $\mathrm{N}$ \\
\hline \multirow{6}{*}{2011} & inc.A & -1.056 & 13.777 & 0.920 & 0.285 & 63 \\
& \&Th & $(0.039)$ & $(0.131)$ & & & \\
& excA & -0.709 & 12.516 & 0.924 & 0.179 & 61 \\
& \&Th & $(0.026)$ & $(0.086)$ & & & \\
& inc.A & -1.060 & 13.736 & 0.918 & 0.287 & 63 \\
& \&Th & $(0.040)$ & $(0.134)$ & & & \\
& excA & -0.709 & 12.462 & 0.928 & 0.179 & 61 \\
& \&Th & $(0.025)$ & $(0.084)$ & & & \\
& inc.A & -1.069 & 13.666 & 0.920 & 0.287 & 63 \\
& \&Th & $(0.040)$ & $(0.133)$ & & & \\
& excA & -0.717 & 12.387 & 0.930 & 0.178 & 61 \\
& \&Th & $(0.025)$ & $(0.084)$ & & & \\
& inc.A & -1.068 & 13.583 & 0.912 & 0.301 & 63 \\
& \&Th & $(0.042)$ & $(0.140)$ & & & \\
& excA & -0.712 & 12.290 & 0.917 & 0.193 & 61 \\
& \&Th & $(0.027)$ & $(0.091)$ & & & \\
\multirow{2}{*}{1971} & inc.A & -1.025 & 13.312 & 0.902 & 0.306 & 63 \\
& \&Th & $(0.043)$ & $(0.142)$ & & & \\
& excA & -0.668 & 12.018 & 0.918 & 0.181 & 61 \\
Errors are in parentheses & $(0.025)$ & $(0.085)$ & & & \\
\hline
\end{tabular}
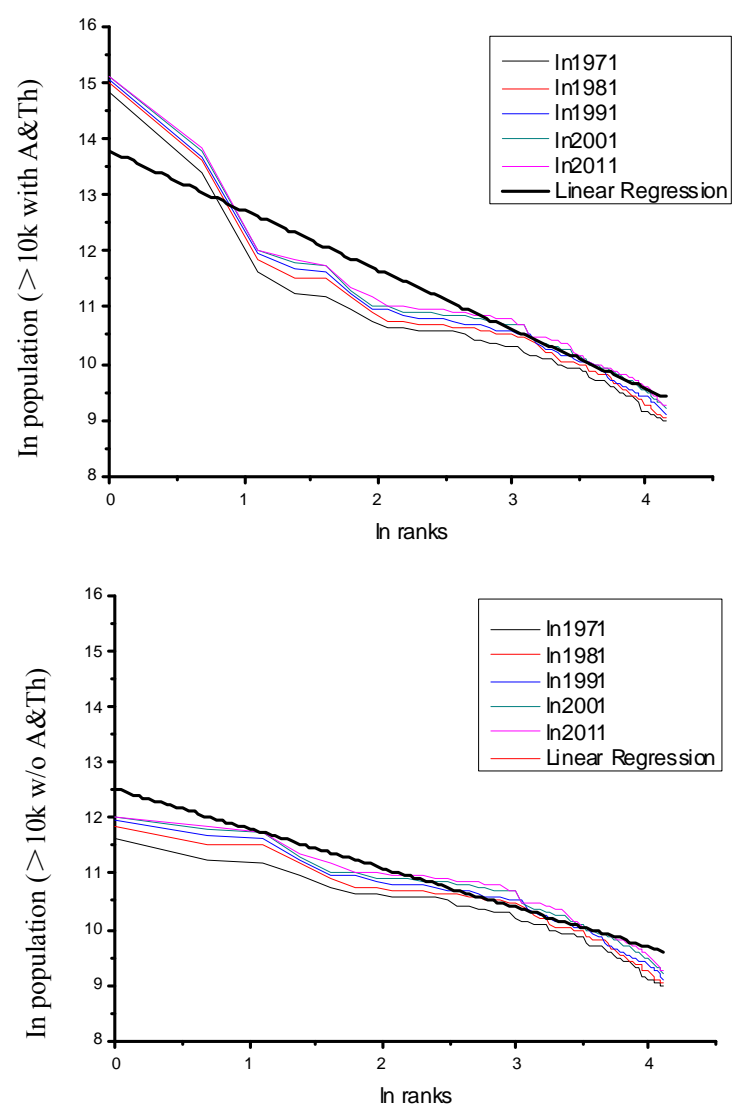

Figure 2. Graphs of logarithms of ranks and population of cities with more than $10 \mathrm{~K}$ inhabitants.

On the contrary, the estimated slopes in the second 
sub-sets-excluding Athens and Thessalonica indicated an upward process caused by the significant increase of population in the considered cities. The slope, $\beta$, is continuously decreased from 1971 to 1991, although in 2001 there was a slight increase. Thus, population distribution according to last census reveals smoothing tendency and though the proportion signifies Zipf's law is strongly rejected in this case.

\subsection{Zipf's Law Validation Test using Population's Density}

At this stage, a rank-size rule is applied to the whole dataset based on their population density. In Table 4 and in Figure 3 a comparison in results of both cases, with and without the two main urban areas, according to OLS method is presented. It is obvious that there is a similarity with previous results for all censuses. Though, in the first sub-sets where Athens and Thessalonica included in analysis, population density complied with Zipf's law. In addition, calculated R-squares and errors boost the accuracy of the estimated results.

On the contrary, it seems that second sub-sets don't comply with Zipf's law as the slope is not close enough to -1 . The distribution of population density in this case seems to be stable in last decades and the estimated slope indicated that there are slight differences regarding population density among cities. Though, the majority of the bigger urban cities with more than $10 \mathrm{~K}$ inhabitants tend to grow in a similar way in terms of their density.

At a second stage, the analysis is applied in urban cities with population of more than $10 \mathrm{~K}$ inhabitants. In this

Table 4. Results of ranks and population density.

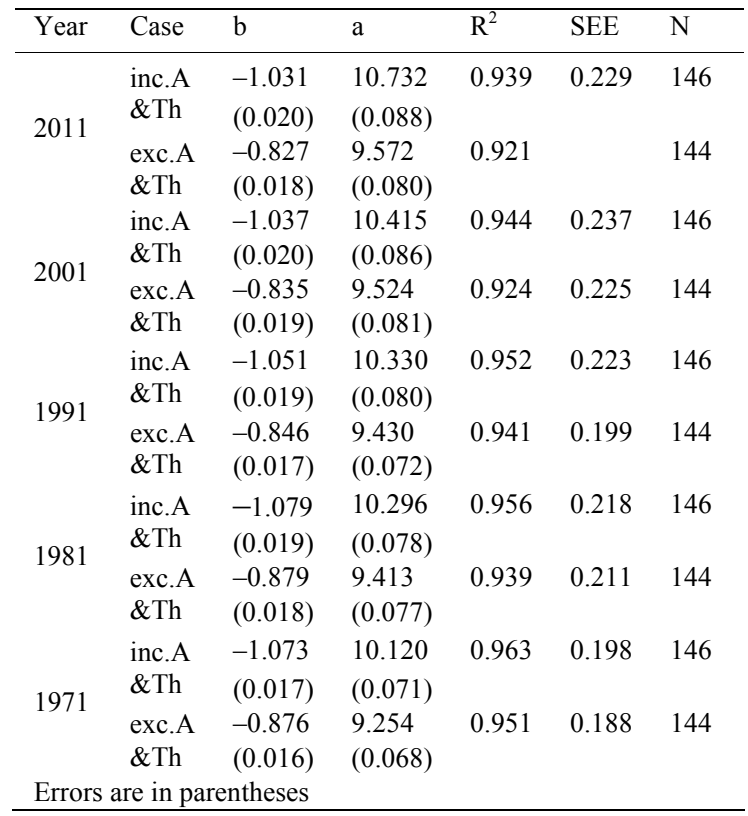

case, as Table 5 and Figure 4 show, population density complied with Zipf's law only in the case where Athens
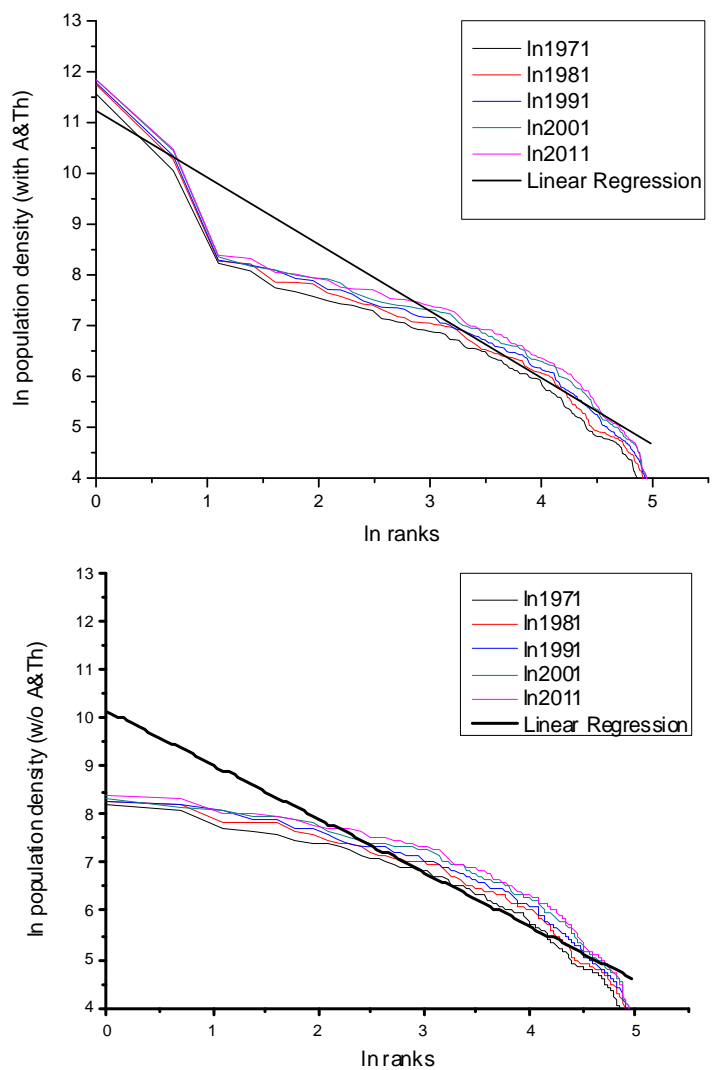

Figure 3. Graphs of logarithms of ranks and population density with and without Athens and Thessalonica.

Table 5. Results of ranks and population density for urban cities with more than $10 \mathrm{~K}$ inhabitants.

\begin{tabular}{|c|c|c|c|c|c|c|}
\hline Year & Case & $\mathrm{b}$ & $\mathrm{a}$ & $\mathrm{R}^{2}$ & SEE & $\mathrm{N}$ \\
\hline \multirow{4}{*}{2011} & inc.A & -0.983 & 10.283 & 0.893 & 0.337 & 63 \\
\hline & $\&$ Th & $(0.043)$ & $(0.142)$ & & & \\
\hline & exc.A & -0.622 & 8.980 & 0.918 & 0.121 & 61 \\
\hline & $\& \mathrm{Th}$ & $(0.023)$ & $(0.078)$ & & & \\
\hline \multirow{4}{*}{2001} & inc. A & -0.957 & 10.188 & 0.874 & 0.331 & 63 \\
\hline & $\& \mathrm{Th}$ & $(0.046)$ & $(0.154)$ & & & \\
\hline & exc.A & -0.580 & 8.826 & 0.951 & 0.119 & 61 \\
\hline & $\& \mathrm{Th}$ & $(0.017)$ & $(0.056)$ & & & \\
\hline \multirow{4}{*}{1991} & inc.A & -0.999 & 10.177 & 0.887 & 0.323 & 63 \\
\hline & $\&$ Th & $(0.045)$ & $(0.150)$ & & & \\
\hline & exc.A & -0.619 & 8.809 & 0.962 & 0.111 & 61 \\
\hline & $\& \mathrm{Th}$ & $(0.016)$ & $(0.052)$ & & & \\
\hline \multirow{4}{*}{1981} & inc.A & -1.011 & 10.096 & 0.902 & 0.302 & 63 \\
\hline & \&Th & $(0.042)$ & $(0.140)$ & & & \\
\hline & exc.A & -0.643 & 8.765 & 0.962 & 0.115 & 61 \\
\hline & $\&$ Th & $(0.016)$ & $(0.054)$ & & & \\
\hline \multirow{4}{*}{1971} & inc. A & -1.018 & 9.964 & 0.911 & 0.288 & 63 \\
\hline & \&Th & $(0.040)$ & $(0.134)$ & & & \\
\hline & exc.A & -0.658 & 8.662 & 0.966 & 0.112 & 61 \\
\hline & $\& \mathrm{Th}$ & $(0.016)$ & $(0.052)$ & & & \\
\hline
\end{tabular}

Errors are in parentheses 

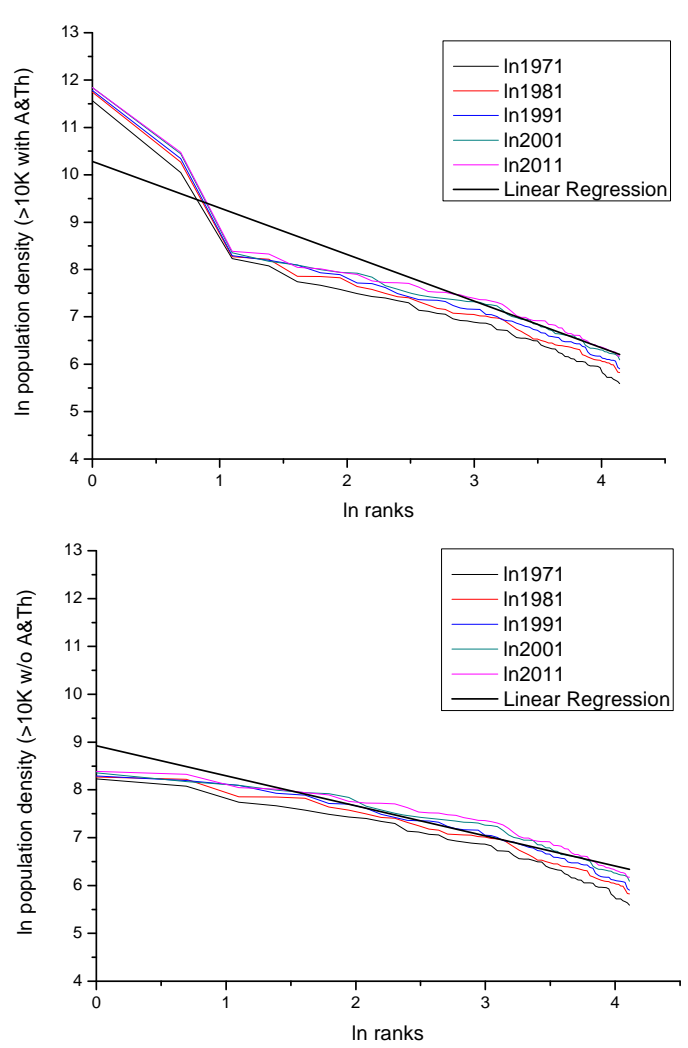

Figure 4. Graphs of logarithms of ranks and population density of cities with more than $10 \mathrm{~K}$ inhabitants.

and Thessalonica included in the analysis. Although there is a slight increase in the slope from -1.018 to -0.983 , in 1971 and 2011 respectively, results are to close to the expected slope of -1 .

On the other hand, based on the results of the other sub-sets-without Athens and Thessalonica the hypothesis of Zipf's law validation is strongly declined. In addition, according to the estimated slope (b) and the intercept (a), it seems that differentiations of population density in urban cities are reduced significantly.

Thus, network infrastructure development e.g. telecommunications network, should be carefully designed. Decision makers should take into account that in these cities the majority of potential users for telecommunications services is concentrated and though the appropriate business models have to apply. The development of high-cost infrastructures, such as fiber to the home networks, maybe should be rejected in areas where economies of scales are not favored by the population density.

\subsection{Zipf's Law Validation Test for Ranks and $\Delta$ (Population)}

Apart from the above tests, the analysis goes ahead with Zipf's law validation tests and exam the distribution of difference in population- $\Delta$ (Population)-among censuses.
Firstly, the net difference between population is calculated, then the rank-size rule is applied to these differences and, finally, the Zipf's law hypothesis is tested. The analysis is conducted for population differentiation regarding the time intervals of years 2011 to 2001, 2001 to 1991,1991 to 1981 and 1981 to 1971.

The results of the applied OLS linear regression are as presented in Table 6 and in Figure 5. Data seem not to comply with Zipf's law as the slope, $\beta$, R-square and Standard Error of Estimate (SEE) have not acceptable values.

Among the 146 examined cities 19, 27 and 22 had a population decrease in 2001, 1991 and 1981 respectively. It is estimated that in 2011 only 10 cities will decrease in terms of population. The average decrease was about $5 \%$ in all censuses (Table 7).

Athens and Thessalonica had the faster population

Table 6. Regression results of ranks and $\Delta$ (Population) for all urban cities.

\begin{tabular}{|c|c|c|c|c|c|c|}
\hline Year & Case & $\mathrm{b}$ & $\mathrm{a}$ & $\mathrm{R}^{2}$ & SEE & $\mathrm{N}$ \\
\hline 2011 & $\begin{array}{l}\text { inc.A } \\
\text { \&Th }\end{array}$ & $\begin{array}{l}-1.127 \\
(0.032)\end{array}$ & $\begin{array}{l}11.917 \\
(0.152)\end{array}$ & 0.878 & 0.414 & 136 \\
\hline 2001 & $\begin{array}{l}\text { exc.A } \\
\& T h\end{array}$ & $\begin{array}{c}-0.989 \\
(0.041)\end{array}$ & $\begin{array}{l}11.102 \\
(0.147)\end{array}$ & 0.798 & 0.395 & 134 \\
\hline 2001 & $\begin{array}{l}\text { inc.A } \\
\& T h\end{array}$ & $\begin{array}{l}-1.180 \\
(0.039)\end{array}$ & $\begin{array}{l}11.866 \\
(0.155)\end{array}$ & 0.879 & 0.411 & 127 \\
\hline 1991 & $\begin{array}{l}\text { exc.A } \\
\& T h\end{array}$ & $\begin{array}{l}-0.994 \\
(0.043)\end{array}$ & $\begin{array}{l}11.060 \\
(0.160)\end{array}$ & 0.808 & 0.455 & 125 \\
\hline $\begin{array}{r}199 \\
-\end{array}$ & $\begin{array}{l}\text { inc. A } \\
\text { \&Th }\end{array}$ & $\begin{array}{l}-1.223 \\
(0.045)\end{array}$ & $\begin{array}{c}11.754 \\
(0.178)\end{array}$ & 0.860 & 0.463 & 119 \\
\hline 198 & $\begin{array}{l}\text { exc.A } \\
\& \text { Th }\end{array}$ & $\begin{array}{l}-1.050 \\
(0.050)\end{array}$ & $\begin{array}{l}11.002 \\
(0.197)\end{array}$ & 0.789 & 0.508 & 117 \\
\hline $\begin{array}{c}1981 \\
-\end{array}$ & $\begin{array}{l}\text { inc. A } \\
\& \text { Th }\end{array}$ & $\begin{array}{l}-1.453 \\
(0.050)\end{array}$ & $\begin{array}{l}12.795 \\
(0.200)\end{array}$ & 0.871 & 0.526 & 124 \\
\hline 1971 & $\begin{array}{l}\text { exc.A } \\
\& T h\end{array}$ & $\begin{array}{l}-1.238 \\
(0.055)\end{array}$ & $\begin{array}{l}11.850 \\
(0.218)\end{array}$ & 0.805 & 0.572 & 122 \\
\hline 015 & 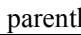 & & & & & \\
\hline
\end{tabular}

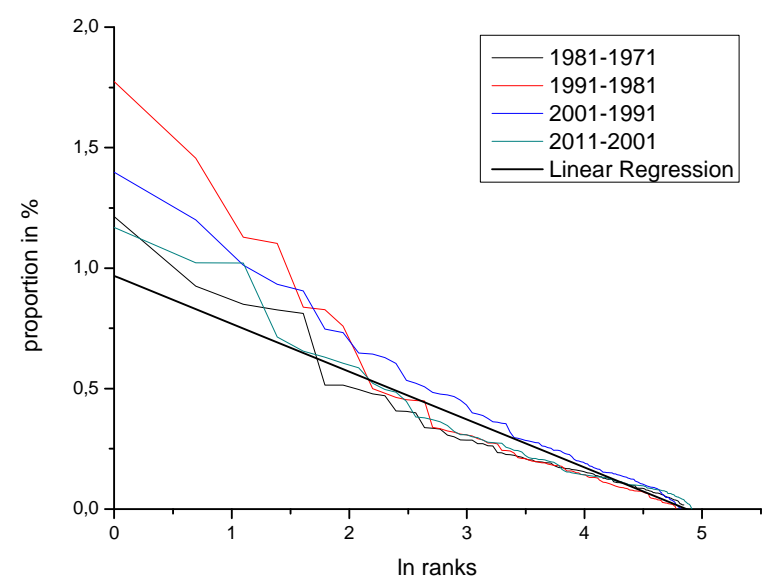

Figure 5. Proportion of population growth expressed in percentage. 
Table 7. Basic statistical measures of cities with negative population growth.

\begin{tabular}{ccccc}
\hline & $2011-2001$ & $2001-1991$ & $1991-1981$ & $1981-1971$ \\
\hline Max & -0082 & -0.169 & -0.173 & -0.168 \\
Min & -0.003 & -0.001 & -0.002 & -0.004 \\
Average & -0.049 & -0.057 & -0.057 & -0.052 \\
Standard & 0.027 & 0.044 & 0.045 & 0.044 \\
Deviation & 10 & 19 & 27 & 22 \\
$\mathrm{~N}$ & & & & \\
\hline
\end{tabular}

growth rate only from 1971 to 1981 and after that they tend to grow more slowly than the other cities. This means that the urbanization process and internal migration to these two big cities have been limited in recent years. Moreover, according to the results, the population growth of the considered urban cities was in general higher in past decades and particularly in ' 80 s.

In order to provide more reliable results, the proportion of population growth is estimated and expressed in percentage. The following Figure 6 shows this population growth for both positive and negative differentiation.

According to Figure 5 and Figure 6, it is concluded that population increase was more intense in last decades. In addition, smaller cities grew in a faster way than the bigger ones. Although the critical mass of population inhabits the two main urban areas, smaller cities are continuously grown and in fact this increase is on the rise.

\section{Discussion of Results}

According to the results, population distribution in Greece complies with the Zipf's law when all urban cities with more than $10 \mathrm{~K}$ inhabitants are included in the analysis. An exception is made by the total population distribution, which complies with the law in the last census. These results indicated that Greek urban cities tend to grow unequally in terms of population. Thus, public policies regarding the deployment of infrastructures such as telecommunications networks should applied in line with population concentration. Apart from public initiatives the private sector should also take into account population distribution, as an indicator of potential users of offered services.

Furthermore, the compliance of ranks and population density is valid with Zipf's law in both cases, for all urban cities and for those with more than $10 \mathrm{~K}$ inhabitants. Although, according to the results when Athens and Thessalonica were excluded from the analysis, data do not comply with the law neither for all urban cities nor with more than $10 \mathrm{~K}$ inhabitants. Though, the choice of the appropriate sample is therefore very important for the further research as it can affect the results, as it is also

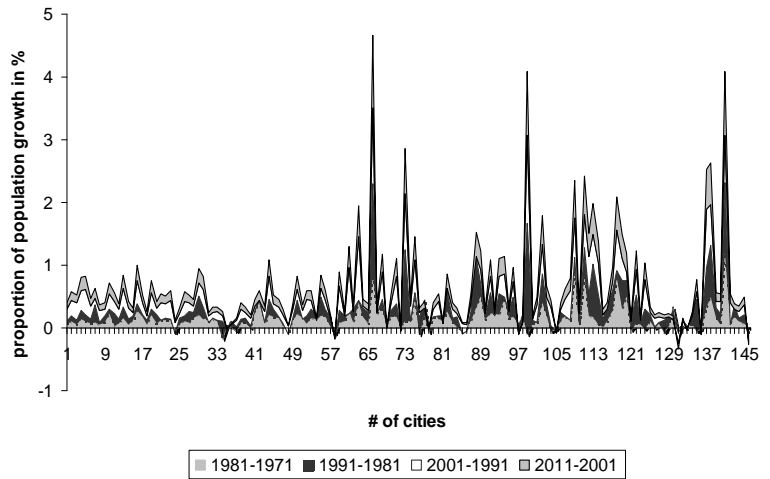

Figure 6. Proportion of population growth expressed in percentage for all urban cities.

stated in [31]. Thus, it can be concluded that the majority of urban cities in Greece, excluding Athens and Thessalonica, have the same population density, which is by far sparser than in the two main urban areas.

Finally, population differentiations have been estimated in order to test the validation of population growth with the Zipf's law and in same time determine the process of this growth in all urban cities. From the analysis is revealed that smaller cities developed in terms of population growth rate faster than bigger ones. Moreover, the development was more intense in $80 \mathrm{~s}$ and in $90 \mathrm{~s}$. In the last decade population growth was significantly limited regarding previous decades. This may indicate that even more urban cities gain the same comparative advantages and people can be befit in the majority of these cities. As Cuberes suggested in [32], the evolution of city growth is sequential and though further analysis could reveal additional information.

As far as the regression is concerned, OLS seems to be acceptable, but it can be observed by the results, that there isn't an absolute linear relationship between population and rank-size for the upper tail of dataset. This observation is inline with other related works [16],[33].

The analysis of the urbanization process along with the validation of the Zipf's law is useful information for policy makers, urban scientists, infrastructure designers, etc. Especially as the debate for power, transport and telecom infrastructure development is increasing, in the light of measures for information society development, this kind of information is particularly useful for more effective broadband population coverage, creation of broadband development, transport design, firms installation (as discussed by Fujiwara et al. [34]), power networks etc.

\section{Conclusions}

Based on the assumption that population characteristics, such as density and growth, contain useful information to be used for decision making of networks' deployment, 
the present work evaluated the application of Zipf's power law over urban cities in Greece. The purpose was the provision of qualitative and quantitative criteria, to both the public and the private sector, in order to decide the development of networks.

Results indicated that public policies regarding the deployment of infrastructures such as telecommunications networks should applied in line with population concentration, not only in terms of public initiatives but from the private sector as well. The private sector should take into account the examined characteristics of the population, in order to estimate the future demand for the offered services and develop the appropriate infrastructures, thus avoiding over or undersupply.

Apart from this, the study provides additional results, according to the distribution of population density and population differentiations during the last decades. It is proved that the considered sample plays a crucial role to the final conclusions, since the acceptance or the rejection of the law depends on it. Moreover, important information regarding the deployment of networks are revealed and discussed.

The approach described in this work can be used as a driver and an input for the construction of strategic plans regarding the deployment of telecommunication or similar type networks.

\section{REFERENCES}

[1] European Commission, "e-Europe 2005, an Information Society for All," European Information Society, 2003.

[2] European Commission, "i2010 - A European Information Society for growth and employment," European Information Society, 2005.

[3] European Commission, "Digital Agenda," European Information Society, 2010.

[4] K. Pigg and L. Crank, "Do Information and Communication Technologies Promote Rural Economic Development?" Journal of the Community Development Society, Vol. 36, No. 1, 2005, pp. 65-76. doi:10.1080/15575330509489872

[5] Y. M. Ioannides and H. G. Overman, "Zipf's Law for Cities: An Empirical Examination," Regional Science and Urban Economics, Vol. 33, No. 2, 2003, pp. 127-137. doi:10.1016/S0166-0462(02)00006-6

[6] D. Black and J. V. Henderson, "Urban Evolution in the USA," Journal of Economic Geography, Vol. 3, No. 4, 2003, pp. 343-373. doi:10.1093/jeg/lbg017

[7] J. V. Henderson, "Cities and Development," Journal of Regional Science, Vol. 50, No. 1, 2010, pp. 515-540. doi:10.1111/j.1467-9787.2009.00636.x

[8] G. K. Zip'f, "Human Behavior and the Principle of Least Effort," Addison-Wesley Press, Cambridge, 1949.

[9] K. Krugman, "Development, Geography, and Economic
Theory," MIT Press, Cambridge, 1995.

[10] L. K. Ha, E. I. Sicilia-Garcia, J. Ming and F. J. Smith, "Extension of Zipf's Law to Words and Phrases," Coling 2002: Proceedings of the 19th International Conference on Computational Linguistics, Taipei, 26-30 August 2002 pp. 315-320.

[11] L. A. Adamic and B. A. Huberman, "Zipf's Law and the Internet," Glottometrics, Vol. 3, 2002, pp. 143-150.

[12] T. Lu, M. C. Costello, P. Groucher, R. Häsler, G. Deuschl and S. Schreiber, "Can Zipf's Law be Adapted to Normalize Microarrays?" BMC Bioinformatics, Vol. 6, 2005, p. 37. doi:10.1186/1471-2105-6-37

[13] G. Kosmopoulou, N. Buttry, J. Johnson, et al., "Sub-urbanization and the Rank-Size Rule," Applied Economics Letters, Vol. 14, No. 1, 2007, pp. 1-4. doi: $10.1080 / 13504850500425675$

[14] V. Nitsch, "Zipf Zipped," Journal of Urban Economics, Vol. 57, No. 1, 2005, pp. 86-100. doi:10.1016/j.jue.2004.09.002

[15] K. T. Soo, "Zipf's Law for Cities: A Cross-Country Investigation," Regional Science and Urban Economics, Vol. 35, No. 3, 2005, pp. 239-263.

doi:10.1016/j.regsciurbeco.2004.04.004

[16] X. Gabaix and Y. M. Ioannides, "The Evolution of City Size Distributions," Vol. 4, In: J. V. Henderson and J. F. Thisse, Eds., Handbook of Regional and Urban Economics, Elsevier, London, 2004, pp. 2341-2378.

[17] Y. Sato and K. Yamamoto, "Population Concentration, Urbanization, and Demographic Transition," Journal of Urban Economics, Vol. 58, No. 1, 2005, pp. 45-61. doi:10.1016/j.jue.2005.01.004

[18] R. E. Lucas, "On the Mechanics of Economic Development," Journal of Monetary Economics, Vol. 22, No. 1, 1988, pp. 3-42. doi:10.1016/0304-3932(88)90168-7

[19] K. Head and T. Mayer, "The Empirics of Agglomeration and Trade," Cities and Geography: North-Holland, Amsterdam, 2004.

[20] M. B. Cunningham, J. P. Alexander and A. Candeub, "Network Growth: Theory and Evidence from the Mobile Telephone Industry," Information Economics and Policy, Vol. 22, No. 1, 2010, pp. 91-102.

doi:10.1016/i.infoecopol.2009.11.005

[21] G. M. Moutafides and A. A. Economides, "Demand for Broadband Access in Greece," Telematics and Informatics, Vol. 28, No. 2, 2011, pp. 125-141. doi:10.1016/j.tele.2010.10.003

[22] F. Guérin-Pace, "Rank-Size Distribution and the Process of Urban Growth," Urban Studies, Vol. 32, No. 3, 1995, pp. 551-562. doi:10.1080/00420989550012960

[23] Hellenic Statistical Authority (E1.Stat), 2010. http://statistics.gr/portal/page/portal/ESYE.

[24] B. Gompertz, "On the Nature of the Function Expressing of the Law of Human Mortality," Philosophical Transactions of the Royal Society, Vol. 36, 1825, pp. 513-585.

[25] C. Urzúa, "A Simple and Efficient Test for Zipf's Law," Economics Letters, Vol. 66, 2000, pp. 257-260. 
[26] R. Kali, "The City as a Giant Component: A Random Graph Approach to Zipf's Law," Applied Economics Letters, Vol. 10, No. 11, 2003, pp. 717-720. doi:10.1080/1350485032000139006

[27] M. Ripeanu, I. Foster and A. Iamnitchi, "Mapping the Gnutella Network: Properties of Large-Scale Peer-to-Peer Systems and Implications for System Design," IEEE Internet Computing Journal Special Issue on Peer-to-Peer Networking, Vol. 6, 2002, pp. 50-57.

[28] "Special Issue on Peer-To-Peer Networking," Internet Computing Journal, Vol. 6, 2002, pp. 50-57.

[29] "Systems and Implications for System Design," IEEE Internet Computing Journal, Vol. 6, 2002, pp. 50-57.

[30] U. Kamecke, "Testing the Rank-Size Rule Hypothesis with an Efficient Estimator," Journal of Urban Economics, Vol. 27, No. 2, 1990, pp. 222-231.

\section{doi:10.1016/0094-1190(90)90016-G}

[31] T. K. Rosen and M. Resnick, "The Size Distribution of Cities: An Examination of the Pareto Law and Primacy," Journal of Urban Economics, Vol. 8, No. 2, 1980, pp. 165-186. doi:10.1016/0094-1190(80)90043-1

[32] D. Cuberes, "Sequential city growth: Empirical evidence," Journal of Urban Economics, Vol. 69, No. 2, 2011, pp. 229-239. doi:10.1016/j.jue.2010.10.002

[33] L. Ellis and D. Andrews, "City Sizes, Housing Costs, and Wealth," Research Discussion Paper, Economic Research Department: Reserve Bank of Australia, 2001.

[34] Y. Fujiwara, C. Di Guilmi, H. Aoyama, M. Gallegati and W. Souma, "Do Pareto-Zipf and Gibrat Laws Hold True? An Analysis with European Firms," Physica A, Vol. 335, No. 1-2, 2004, pp. 197-216. doi:10.1016/i.physa.2003.12.015 